\title{
TOPOGRAFIA DAS ABERTURAS DOS DUCTOS PAROTÍDICOS DE UM LOBO GUARÁ (Chrysocyon brachyrus ILLIGER, 1811)
}

\author{
TOPOGRAPHY OF THE OPENINGS OF THE PAROTIDICS DUCTS OF \\ A “GUARA” WOLF (Chrysocyon brachyrus ILLIGER, 1811)
}

\author{
André Luiz Quagliatto Santos ${ }^{1}$, Eduardo Maurício Mendes de Lima ${ }^{2}$
}

\section{- RELATO DE CASO -}

Estudou-se a topografia dos pontos de abertura dos ductos parotídicos no vestíbulo da boca de um lobo guará (Chrysocyon brachyrus), fêmea, adulto, proveniente do Zoológico do Parque do Sábia, da cidade de Uberlândia, Minas Gerais, Brasil. Realizaram-se incisões horizontais nas paredes do vestíbulo da boca, a cada lado, até um ponto das comissuras labiais que permitiam a identificação das aberturas dos ductos parotídicos, bem como suas relações com as faces vestibulares dos dentes pré-molares e molares superiores. Nessa oportunidade, pôde-se observar que, nesse animal, os ductos parotídicos abrem-se em correspondência ao primeiro dente molar superior.

Palavras-chave: Chrysocyon brachyrus, glândula parótida, anatomia.

\section{SUMMARY}

Topography of the opening points of the parotid ducts into the vestibule of the mouth from a female adult "guara" wolf (Chrysocyon brachyrus) coming from the Sabia Park Zoo in the city of Uberlândia, Minas Gerais, Brazil, was studied. Horizontal incisions were performed on the walls of the vestibule of the mouth on each side up to the point of the labial comissure that allowed the identification of the parotid duct openings as well as its relationships with the vestibular surface of the premolar and upper molar teeth. In this opportunity, it could be observed that, in this animal, the parotid ducts open into in correspondence to the upper first molar tooth.

Key words: Chrysocyon brachyrus, parotid gland, anatomy.

\section{INTRODUÇÃO}

O conhecimento da localização exata e de possíveis alterações da abertura oral do ducto excretor da glândula parótida reveste-se de particular importância, face ao desenvolvimento do uso de técnicas mais acuradas; tal seja a sialografia, na detecção de processos patológicos, desde traumáticos até tumorais da referida glândula ou de suas vias de escoamento.

A respeito da nomenclatura adotada para animais domésticos, os tratadistas consideram e designam, genericamente, através de enumeração dos molares em geral (incluindo os pré-molares), no sentido rostro caudal, mas seguindo direção inversa, ao particularizarem os pré-molares, de forma tal, que o primeiro deles representa o quarto dos registros clássicos. Os autores consideram como molares, tanto esses como os pré-molares, sendo possível, entretanto, identificá-los com exatidão através de ilustrações ou comentários seqüentes nesses relatos. Assim, descrevem a papila parotídica como sendo uma saliência na mucosa do vestíbulo da boca, vista, segundo BRADLEY (1935), SISSON \& GROSSMAN (1975), NICKEL et al. (1981) e GETTY (1986), em nível do 3ํำ dente pré-molar da arcada superior, informação que é semelhante à de

\footnotetext{
${ }^{1}$ Professor Titular do Departamento de Morfologia da Universidade Federal de Uberlândia.

2 Acadêmico do curso de Medicina Veterinária da Universidade Federal de Uberlândia. E-mail: limaemm@ triang.com.br. Rua XV de Novembro 365, apto 2000,38400 - 214. Uberlândia - MG. 
MARTIN (1912) embora este empregue a designação de $3^{\mathrm{o}}$ molar (pré-molar) superior. LESBRE (1922), BOURDELLE et al. (1953) e ELLENBERGER \& BAUM (1977) situam-na defronte ao espaço compreendido entre o $3^{\circ}$ e $4^{\circ}$ molar (pré-molar), guardando a ressalva já feita quanto à nomenclatura.

Ressalta-se que BRUNI \& ZIMMERL (1947) e SCHWARZE \& SCHRÖDER (1972) localizam a papila parotídica à altura do intervalo existente entre o $3^{\underline{O}}$ e o $4^{\underline{O}}$ pré-molar, da arcada dentária superior. DYCE $\boldsymbol{e t}$ al. (1990) consideram que o ducto da glândula parotída encontra-se em nível do $4^{\underline{0}}$ pré-molar superior. FERNANDES FILHO et al. (1992) consideram, geralmente, a papila parotídica apresentando-se em nível do espaço entre o $4^{\underline{0}}$ pré-molar e o $1^{\underline{0}}$ molar da arcada superior, mas surgindo, também, topograficamente relacionada a outros dentes ou espaços interdentais; foram observados, ainda, algumas variações na predominância de localização, associadas aos quatro tipos de cabeças analisadas por esses autores. Por outro lado, EVANS (1993) relata que a papila parotídica está localizada opostamente à margem caudal do $4^{\underline{0}}$ pré-molar superior.

De fato, as diversas formas as quais os autores apresentam a topografia de desembocadura do ducto parotídico nos animais domésticos, motivaram a busca de dados atinentes a esse respeito em um lobo guará (Chrysocyon brachyrus). Salienta-se, ainda, a importância de acrescentarem-se dados à anatomia comparada, e em especial a esse mamífero.

\section{RELATO DO CASO}

A situação da desembocadura do ducto parotídico, uma vez que não foi observada a presença da papila parotídica, relativamente aos dentes prémolares e molares superiores, foi examinada em um exemplar fêmea de lobo guará (Chrysocyon brachyrus), doado após a morte pelo Zoológico do Parque do Sábia, da cidade de Uberlândia, Minas Gerais, Brasil, para o Departamento de Morfologia da Universidade Federal de Uberlândia.

Com auxílio de instrumental cirúrgico, realizaram-se incisões horizontais nas paredes do vestíbulo da boca, a cada lado, até um ponto das comissuras labiais que permitiram a identificação da desembocadura dos ductos parotídicos, de forma a determinar-se a relação topográfica da focada estrutura com os dentes pré-molares e molares da arcada superior. Para fins de ilustração, foi efetuada fotografia do crânio do lobo guará (Chrysocyon brachyrus) (Figura 1).

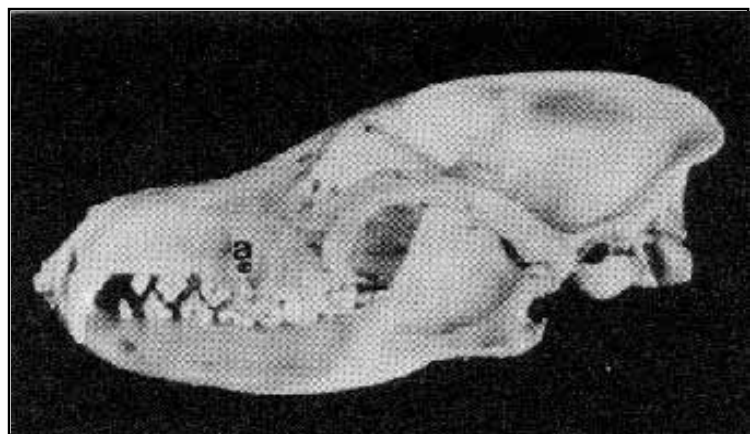

Figura 1 - Fotografia da vista lateral do crânio de um lobo guará, mostrando o ponto de desembocadura da glândula parótida (a), em nível do $1^{\circ}$ dente molar superior.

\section{RESULTADO E DISCUSSÃO}

No estudo da localização do ponto de desembocadura do ducto excretor da glândula parótida, realizado em um lobo guará (Chrysocyon brachyrus), tomando como ponto de reparo os dentes da arcada superior, foi observado a abertura do ducto em nível da linha de projeção lateral do primeiro dente molar superior. Essa disposição ocorre tanto no antímero esquerdo quanto no direito, mostrando, assim, existir simetria bilateral quanto ao posicionamento do referido ponto.

Através dos achados, e salientando que, em se tratando de um animal silvestre em vias de extinção, deve-se considerar a existência de variações topográficas, em relação ao ponto de desembocadura do ducto parotídico, em outros da mesma espécie. Esse estudo tem que ser visto como ponto de partida para posteriores investigações a respeito da anatomia desse tão importante componente da fauna brasileira. Ao buscar-se as informações fornecidas por diversos tratadistas e, ainda, por alguns pesquisadores, esses apresentam, em seus relatos, que mesmo em animais da mesma espécie existem variações em relação ao ponto de desembocadura do ducto parotídico; apresentando assim, distintas localizações em relação aos dentes pré-molares e molares da arcada superior.

Comprovando esse fato, tem-se as informações fornecidas por MARTIN (1912), BRADLEY (1935), SISSON \& GROSSMAN (1975), ELLENBERGER \& BAUM (1977), NICKEL $\boldsymbol{e t}$ al. (1981) e GETTY (1986), que citam como sendo ponto de referência da localização da papila parotídica o $3^{\circ}$ pré-molar superior.

E, ainda, para LESBRE (1922), BRUNI \& ZIMMERL (1947), BOUERDELLE et al. (1953) e SCHWARZE \& SCHRÖDER (1972), a papila parotídica ocorre em nível do espaço compreendido entre o $3^{\circ}$ e o $4^{\circ}$ pré-molares superiores. BRUNI \& 
ZIMMERL (1947) destacam nos carnívoros a peculiaridade de numeração dos molares e prémolares,utilizada por SCHWARZE \& SCHRÖDER (1972), ou seja, seguindo para os primeiros dentes mencionados o sentido rostro caudal e, para os últimos, o caudo rostral. DYCE et al. (1990) relatam que o ducto da glândula parótida abre-se opostamente ao $4^{\circ}$ pré-molar superior. Ainda FERNANDES FILHO $\boldsymbol{e t} \boldsymbol{a l}$. (1988), em cães de raças, agrupadas segundo quatro tipos de cabeças, encontraram a papila parotídica deslocando-se desde o limite compreendido entre a margem aboral do $2^{\mathrm{o}}$ pré-molar e a oral do $3^{\circ}$, até o espaço entre o $1^{\mathrm{o}}$ e o $2^{-}$molares; e ainda referendadas, também, à face bucal do $3^{\circ}$ e do $4^{\circ}$ pré-molares, $1^{\circ}$ molar ou, aos espaços que, pela ordem, guardam entre si. A confirmação da ocorrência do ducto parotídico em nível do $1^{\circ}$ molar superior, citada por FERNANDES FILHO et al. (1988), coincide com a simetria bilateral também encontrada no lobo guará (Chrysocyon brachyrus).

Por sua vez, EVANS (1993), de maneira precisa em suas citações, considera a papila parotídica ocorrendo ao nível da margem caudal do $4^{\circ}$ pré-molar superior.

\section{CONCLUSÃO}

Conclui-se que ocorre simetria bilateral na abertura do ducto da glândula parótida, em nível do $1^{\circ}$ dente molar da arcada superior do lobo guará.

\section{AGRADECIMENTOS}

Agradecemos ao Zoológico do Parque do Sábia, por ter-nos cedido o material utilizado neste trabalho.

\section{REFERÊNCIAS BIBLIOGRÁFICAS}

BOURDElle, E., BRESSOU, C., MONTANE, L. Anatomie reginale des animaux domestiques. Paris : Bailliere, 1953. $4 \mathrm{v}$.

BRUNI, A.C., ZIMMERL, V. Anatomia degli animali domestici. Milano : Dr. Francesco Vallardi, 1947. 2v.

BRADLEY, O.C. Topographical anatomy of the dog. 3ed. London: Oliver and Boyd, 1935. 319p.

DYCE, K.M., SACK, W.O., WENSING, C.J.G. Tratado de anatomia veterinária. Rio de Janeiro : Guanabara Koogan, 1990. 567 p.

ELLENBERGER, W., BAUM, H. Handbuch der vergleichenden anatomie der haustiere. 18 ed. Berlin : Springer, 1977. 590p.

EVANS, H.E. Miller's anatomy of the dog. 3ed. Philadelphia : Saunders, 1993. 1113p.

FERNANDES FILHO, F.A., D'ERRICO, A.A., PEDUTI NETO, J., et al. Localização topográfica da papila parotídea em cães de raça. Revista da Faculdade de Medicina Veterinária e Zootecnia da Universidade de São Paulo, São Paulo, v.25, n.1, p.81-91, 1988.

GETTY, R. Sisson/Grossman Anatomia dos animais domésticos. 5 ed. Rio de Janeiro : Guanabara Koogan, 1986. $2 \mathrm{v}$.

LESBRE, F.X. Précis d'anatomie comparée des animaux domestiques. Paris : Bailleère, 1922. 385p.

MARTIN, P. Lehrbuch der anatomie der haustiere. Stuttgart : Schickhardt \& Ebner, 1912. 285p.

NICKEL, R., SCHUMMER, A., SEIRFELE, A. The viscera of the domestic mammals; The circulatory system, the skin, and cutaneous organs of the domestic mammals. BerlinHamburg: Verlag Paul Parey, 1981. 3v.

SCHWARZE, E., SCHRÖDER, L. Compêndio de anatomia veterinária. Zaragoza: Acribia, 1972. 2v.

SISSON, S., GROSSMAN, J.D. Anatomia de los animales domesticos. Barcelona: Salvat, 1975. 972p.

Ciência Rural, v. 31, n. 2, 2001. 